\title{
Storage stability of SBS/sulfur modified bitumens at high temperature: Influence of bitumen composition and structure
}

\author{
Íñigo Aguirre de Carcer $^{a}$, Rosa M. Masegosa ${ }^{a}$,*, M. Teresa Viñas ${ }^{a}$, Marta Sanchez-Cabezudo ${ }^{a}$, \\ Catalina Salom ${ }^{b}$, Margarita G. Prolongo ${ }^{b}$, Verónica Contreras ${ }^{c}$, Francisco Barceló ${ }^{c}$, Antonio Páez ${ }^{c}$ \\ a E.U.I.T. Aeronáutica, Universidad Politécnica de Madrid, Spain \\ ${ }^{b}$ E.T.S.I. Aeronáuticos, Universidad Politécnica de Madrid, Spain \\ ${ }^{c}$ Repsol, CTR, 28931 Móstoles, Madrid, Spain
}

\begin{abstract}
- The composition of bitumen affects the storage stability of hot SBS modified bitumens. - Aromatic content of $40 \%$ and solid phase volume lower than $22 \%$ improve the stability.

- The increase of solid phase content hinders the dispersion of the SBS rich phase.

- Changes of the physical properties at $160^{\circ} \mathrm{C}$ are related to the biphasic morphology.
\end{abstract}

Keywords:

SBS copolymer

Polymer modified bitumen

Thermal stability

Phase separation

Structure
Polymer modified bitumens, PMBs, are usually prepared at high temperature and subsequently stored for a period of time, also at high temperature. The stability of PMBs, in these conditions, has a decisive influence in order to obtain the adequate performances for practical applications. In this article the attention is focused in the analysis of the factors that determine the stability of styrene-butadienestyrene copolymer (SBS)/sulfur modified bitumens when the mixtures are maintained at high temperature. Bitumens from different crude oil sources were used to prepare SBS/sulfur modified bitumens. Changes in the values of viscosity, softening point, as well as in the morphology of PMB samples, stored at $160^{\circ} \mathrm{C}$, were related to the bitumen chemical composition and to the amount of asphaltene micelles present in the neat bitumen used in their preparation.

\section{Introduction}

Polymer modified bitumens (PMBs) are widely used for paving roads. It has been widely shown that the presence of polymer in PMBs considerably improves its performance over a wide range of temperatures. In general, polymer modified bitumens display improved properties with respect to neat bitumens, increasing resistance to permanent deformation at relatively high temperatures without leading to deterioration of their properties at low temperatures.

Due to the structural complexity of bitumen, in the literature there are several models describing its behavior [1-5]. The colloidal model attributed to Nellensteyn [1] and later developed

\footnotetext{
* Corresponding author. Address: E.U.I.T. Aeronáutica, Universidad Politécnica de Madrid, Plaza de Cardenal Cisneros no. 3, 28040 Madrid, Spain. Tel.: +34 91 3367483 (101).

E-mail address: rosamaria.masegosa@upm.es (R.M. Masegosa).
}

by Pfeiffer and Saal [2] is one of the most used to explain unique aspects of the bitumen properties. According to the colloidal model the bitumens were classified in three categories according their structure and rheological behavior. Sol-bitumens (Newtonian behavior) characterized by the existence of asphaltenes micelles isolated fully dispersed in maltenic phase, gel-bitumens (nonNewtonian behavior) characterized by the presence of asphaltene micelles interconnected forming a network, and finally, the solgel bitumens with an intermediate structure. Subsequent investigations have failed to demonstrate the existence of a gel-like structure in the bitumens [6]. Therefore, under the current knowledge, the differences of behavior of paving grade bitumens is only a matter of the low or high content of the solid fraction present in their structure [6].

All commercial PMBs, called compatible, are heterogeneous on a microscopic scale, although macroscopic inspection indicates homogeneity. When a polymer is added to the bitumen, the polymer swells absorbing part of the lighter aromatic components of 
the bitumen. The swollen polymer makes up the polymer-rich phase. At low concentrations of polymer, this phase is dispersed in a continuous asphaltene rich phase [6]. The biphasic structure of these systems is the key to improve the behavior of the PMB in relation to neat bitumen. Completely miscible PMBs have also been studied but their properties are very similar to those of neat bitumen. For this reason the total miscibility is not appropriate to achieve a significant improvement in properties compared to pure bitumen.

The thermodynamic equilibrium of PMBs corresponds to the total separation of the coexisting phases; this separation may occur during storage if the system has enough time and mobility. Accordingly, one of the main problems is to maintain polymer-bitumen mixture stable during the preparation and subsequent storage period at high temperature [7]. It has been demonstrated [8,9] that the stability of the PMB's depends on factors such as chemical composition and structure of the bitumen and polymer, and factors related to the operating conditions of the mixing procedure, including temperature, time and stirring speed.

There are different kinds of polymers used in the preparation of PMBs [10], polymers such as styrene butadiene rubber (SBR), ethylene vinyl acetate (EVA) and ethylene glycydyl acrylate (EGA) have been used. One of the most used polymers in the manufacture of PMBs is styrene-butadiene-styrene block copolymer (SBS) [7-11]. SBS polymers are available as linear, radial or branched copolymers. Radial SBS structure is formed by rigid styrene domains that act as physical crosslinks conferring resistance to the material, connected with butadiene segments of elastomeric nature that confer elasticity to SBS. In the temperature range between the glass transition temperatures of the elastomeric blocks $\left(-80^{\circ} \mathrm{C}\right)$ and the rigid blocks $\left(70^{\circ} \mathrm{C}\right)$, SBS behaves as an elastomer.

SBS modified bitumens may not be fully stable when kept at high temperature during a large period of time, due to the differences in the solubility parameter and density between SBS and bitumen $[7,9,11]$. In such systems, it is usual to add sulfur during the preparation process to increase the stability. The sulfur reacts with the alkene moieties present in SBS, creating chemical crosslinks which help to stabilize the system $[8,9,12]$.

In the literature there are numerous articles dedicated to investigate the stability behavior and the morphology of PMB́s, analyzing the influence of aging [13-15], the use of graft copolymers containing ending reactive groups $[7,16]$, the effect of the vulcanization reaction [8,12], the influence of polymer parameters such us, content [11], molecular weight [9], or even the chemical nature of the polymer $[17,18]$. However there are fewer studies dedicated to analyze the influence of the nature of the bitumen and its structure on the storage stability at high temperature of PMBs [9].

This paper is focused on the study of the stability behavior of SBS modified bitumens in the presence of sulfur. The study has two objectives, to analyze the influence of the structure and composition of the bitumen on the stability and to check the change in the properties produced by the storage of the SBS bitumen mixtures at high temperature $\left(T=160^{\circ} \mathrm{C}\right)$. Bitumens from different crude oil sources have been selected for this study. The bitumens have been chemically characterized by SARA fractioning, and Xray diffractometry has been used for structural characterization of asphaltene fractions. The SBS bitumen blends have been prepared using different bitumens mixed with $3 \mathrm{wt} \%$ of SBS, relative to the bitumen content. For these samples the macroscopic physical properties, such as viscosity, penetration, softening point, and storage stability have been determined. Finally the storage stability at high temperature of SBS modified bitumens is discussed in terms of the structure and composition of the bitumens used in their preparation.

\section{Materials and methods}

\subsection{Materials}

In order to prepare SBS modified bitumens differing in structure and composition, the procedure shown in Scheme 1 has been followed. The starting point corresponds to four bitumens supplied by Repsol, with different penetration values belonging to different crude oil sources, arabian (A17, A570) and maya (M18 M172). Mixing of these pairs of bitumens allows the manufacture of two new bitumens, A100 and M100, which differ in the crude oil source but have penetration values around $100 \mathrm{dmm}$. Finally $\mathrm{A} 100$ and $\mathrm{M} 100$ are mixed in appropriate amounts in order to obtain bitumens, with penetration values around $100 \mathrm{dmm}$, designated as M/A, that will be subsequently modified with SBS. For clarification, M20/A80 bitumen contains $20 \mathrm{wt} \%$ of M100 bitumen and $80 \mathrm{wt} \%$ of A100 bitumen. The separation of bitumens into four generic fractions was performed by column chromatography (ASTM D4124-01). The asphaltene content of the bitumens was determined by $n$-heptane extraction. Subsequently deasphalted fraction was separated using different eluents. Heptane, toluene, methanol/toluene (50/50) and trichloroethylene were used to extract saturates, aromatics and resins fractions for each bitumen, respectively.

In order to characterize the macroscopic physical properties of the bitumens conventional test methods such as penetration test, viscosity test and softening point test were performed. The results are shown in Table 1.

The modifying polymer, supplied by Dynasol, was the styrene-butadiene-styrene (SBS) block copolymer, Calprene 411 , a radial polymer containing $30 \mathrm{wt} \%$ styrene and $70 \%$ of butadiene and an average molecular weight $M_{w}=300 \times 10^{3}$.

\subsection{Preparation of samples}

SBS modified bitumens were prepared by melt blending using a high shear mixer Silverson L4RT. $500 \mathrm{~g}$ of bitumen samples placed in a metal container were heated and stirred at $T=190^{\circ} \mathrm{C}$, then $3 \mathrm{pph}$ of SBS polymer was added gradually and stirring was maintained at $5000 \mathrm{rpm}$ for $5.5 \mathrm{~h}$. Finally, for vulcanizing $0.05 \mathrm{pph}$ of sulfur and $0.075 \mathrm{pph}$ of $\mathrm{ZnO}$ were added to the blend, while the stirring was continued for 30 min under the same stirring conditions. All amounts are referred to the amount of bitumen in the blends. It is worthy mention that the physical properties of neat bitumens did not undergo significant changes when the bitumens were subjected to the same process used to prepare blends with SBS.

\subsection{Test methods and storage stability}

The base bitumens and SBS modified bitumens were subjected to the following conventional tests: penetration (UNE-EN 1426), softening point (UNE-EN 1427) and viscosity (UNE-EN 12595:2007). Viscosity measurements were performed in a Brookfield Model DV-II + Pro viscometer at $T=135^{\circ} \mathrm{C}$.

Aluminum toothpaste tubes ( $32 \mathrm{~mm}$ in diameter and $160 \mathrm{~mm}$ in height) filled with vulcanized SBS modified bitumens have been used for determining the storage stability of the blends. Difference between softening points of the blends fractions placed at the top and at the bottom of the tubes has been determined after maintaining them in vertical position for $72 \mathrm{~h}$ at $160^{\circ} \mathrm{C}$.

\subsection{Infrared spectroscopy (FTIR)}

A FT-IR Nicolet 6700 spectrometer was used to determine the distribution of polymer rich phase in the samples subjected to stability test. IR spectra were recorded in the range $600-4000 \mathrm{~cm}^{-1}$, and the standard analytical conditions were 32 scans, resolution $4 \mathrm{~cm}^{-1}$ and transmission mode. Solutions of $5 \mathrm{wt} \%$ of SBS modified bitumens in dichloromethane were prepared. Subsequently these solutions were dropped onto a $\mathrm{KBr}$ disk and finally dried in a dry nitrogen stream.

Table 1

Properties of the bitumens.

\begin{tabular}{llll}
\hline Bitumen & $\begin{array}{l}\text { Penetration } \\
25^{\circ} \mathrm{C}(0.1 \mathrm{~mm})^{\mathrm{a}}\end{array}$ & $\begin{array}{l}\text { Softening } \\
\text { point }\left({ }^{\circ} \mathrm{C}\right)^{\mathrm{b}}\end{array}$ & $\begin{array}{l}\text { Viscosity } \\
135^{\circ} \mathrm{C}(\mathrm{Pa} \cdot \mathrm{s})^{\mathrm{c}}\end{array}$ \\
\hline M172 & 172 & 44 & 0.22 \\
M18 & 18 & 66 & 1.65 \\
A17 & 17 & 61 & 1.02 \\
A570 & 570 & 30 & 0.96 \\
A100 & 100 & 45 & 0.27 \\
M100 & 103 & 44 & 0.35 \\
M80/A20 & 102 & 45 & 0.31 \\
M60/A40 & 104 & 45 & 0.3 \\
M40/A60 & 104 & 44 & 0.29 \\
M20/A80 & 103 & 45 & 0.28 \\
\hline
\end{tabular}

a UNE-EN 1426.

b UNE-EN 1427.

c UNE-EN 12595:2007. 


\subsection{X-ray diffractometry}

X-ray diffractometer X́pert-PRO ALPHA 1 with fast X́celerator detector operating at $45 \mathrm{kV}$ and $40 \mathrm{~mA}$ was used to obtain the diffractograms of powdered asphaltenes samples. The diffraction patters $\left(2 \theta=3-110^{\circ}\right)$ were recorded at room temperature using $\mathrm{Cu} K \alpha 1$ radiation $(\lambda=1.5406 \AA)$ by continuous scanning with a step size of $0.1^{\circ}$. Using adequate software the backgrounds were subtracted from the diffractograms and the overlapped bands deconvoluted in order to obtain peak position, peak intensity, area and width of the band at half maximum for each of the bands.

\subsection{Fhorescence microscopy}

Small amounts of hot SBS modified bitumen samples were deposited over slides and viewed under a Leica DM100 microscope with a 400x magnification at room temperature. The microscope was equipped with a UV lamp and a filter in the range $390-490 \mathrm{~nm}$.

\section{Results and discussion}

\subsection{Bitumen characterization}

Bitumens are very complex materials which consist of numerous species of hydrocarbons. Depending on their origin, the chemical composition of the bitumen can change significantly. The stability of SBS-modified bitumens is determined mainly by the interaction between SBS and the aromatic fraction of bitumen [6]. Consequently, the aromatic fraction is compromised between the need to interact with the polymer giving rise to polymer swelling and the need to maintain the colloidal equilibrium of bitumen in order to keep the stability of SBS modified bitumen. On the other hand, taking into account that polymers and asphaltenes do not mix, the content of asphaltenes will be another factor to consider when analyzing polymer-bitumen stability.

The macroscopic physical properties and SARA fractions of the bitumens used are shown in Table 1 and Figs. 1 and 2. The data for A100 and M100 bitumens and their blends M/A, shown in Fig. 2, have been obtained from the data in Fig. 1 taking into account the amounts of the bitumens M18, M172, A17 and A570 used their respective fabrication.

Bitumens with high aromatic/asphaltene ratios favor the stability of bitumen and polymer mixtures. Fig. 2 shows, for the M/A bitumen series, a gradual change of aromatic/asphaltene ratio from A100 bitumen to M100 bitumen. Therefore, it can be expected that bitumens with a higher proportion of maya bitumens would be less stable with the polymer.

However this statement does not consider that, according to the colloidal model, the asphaltenes in the bitumen are surrounded by a solvation shell of solid resins forming micelles, making the total fraction of solids dispersed in the maltene matrix higher than that obtained by considering only the solid asphaltene content obtained in the SARA fraction. It has been demonstrated that the increase in the fraction of the solid phase due to the surfactant resins, has importance in the rheological behavior of bitumens $[6,19,20]$. The thickness of this solvation shell is a function of the type of bitumen, asphaltene content and temperature [6,19]. Consequently, it would be expected that bitumens, with similar content of asphaltenes,

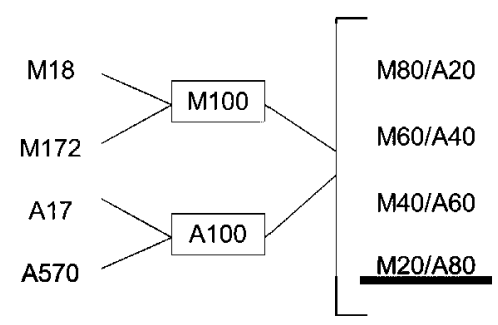

Scheme 1. Mixtures of bitumens used in the preparation of SBS modified bitumen.

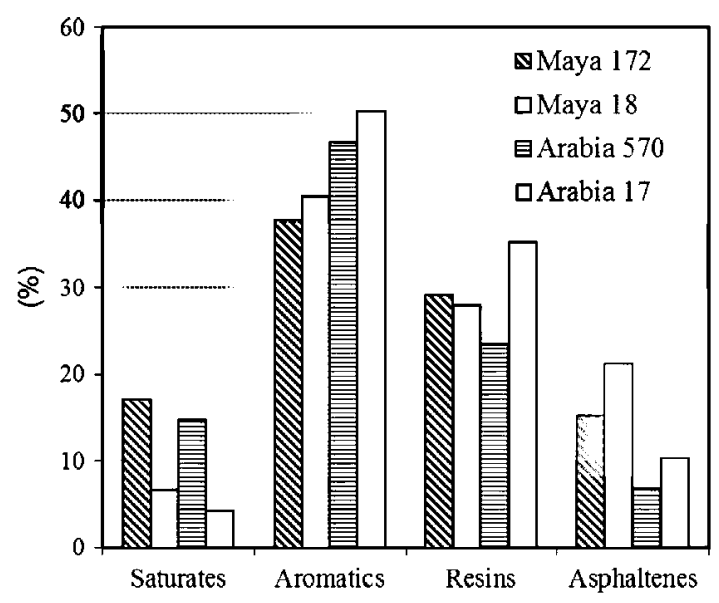

Fig. 1. SARA fractions for arabian and maya bitumens.

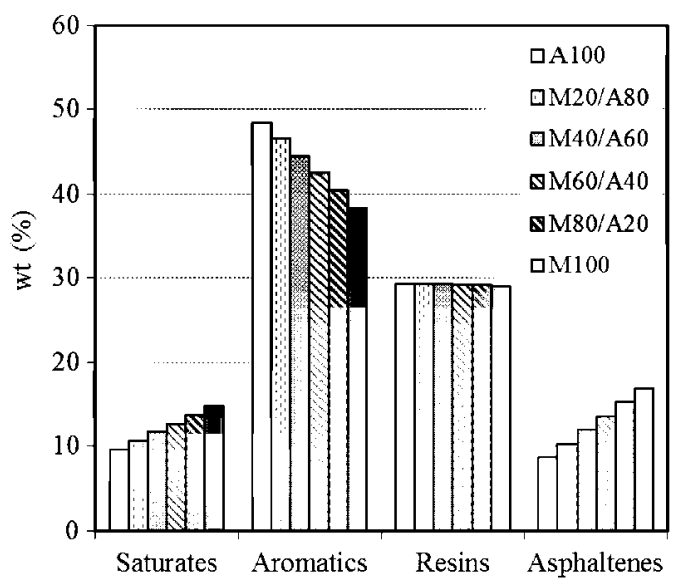

Fig. 2. SARA fractions for A100, M100 and M/A bitumens.

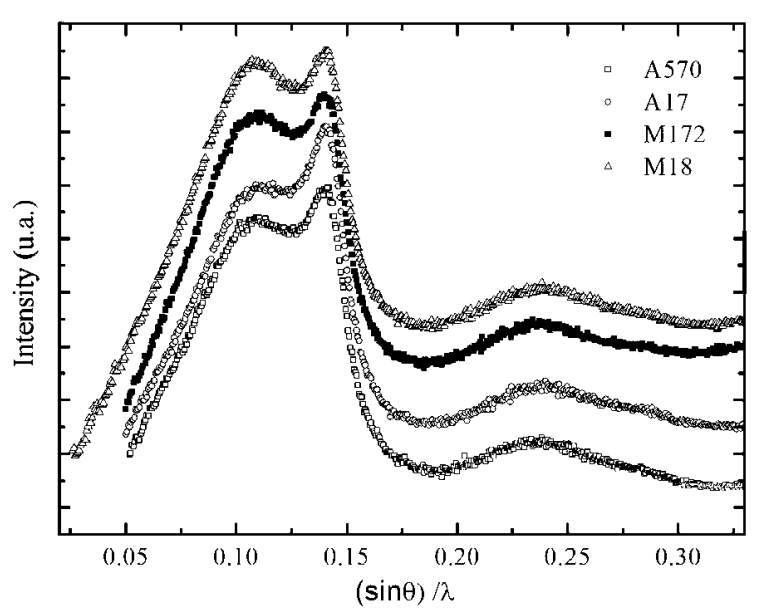

Fig. 3. X-ray diffraction patterns for asphaltene fractions.

could have different percentage of solid phase, depending on their origin or the temperature at which they are stored. This circumstance will certainly have influence in the polymer stability behavior and deserves to be taken into account.

Asphaltenes are comprised mainly by clusters of condensed aromatic rings, often containing heteroatoms, bound to saturated 
rings and long aliphatic chains. The structure of maya and arabian asphaltenes has been studied by X-ray diffractometry measurements. The X-ray diffraction patterns of dust samples of arabian and maya asphaltenes were obtained at room temperature, and the results are displayed in Fig. 3.

The diffractograms show three independent bands according to literature, the $\gamma$-band and the 002-band overlapped in the region of $\sin \theta / \lambda=0.05-0.15$, and a third band, 10 -band, located at $\sin \theta /$ $\lambda \sim 0.24$. Using adequate software the backgrounds were subtracted from the diffractograms and the overlapped bands deconvoluted in order to obtain peak position, peak intensity, area and width of the band at half maximum for each of the bands.

From the $\gamma$-band and 002-band it is possible to calculate the distance between aliphatic chains or saturated rings, $d \gamma$, and the distance between two aromatic layers of condensed aromatic rings, $d_{m}$, applying the Brag law, as:

$d_{i}=\frac{\lambda}{2 \sin \theta}$

where the subscript $i$ correlate to $\gamma$ or $m$ and $\theta$ indicates the peak position of the $\gamma$-band or 002 -band, respectively.

The diameter of the aromatic cluster perpendicular to the plane of the aromatic sheets, $L_{c}$, can be obtained from $W_{1 / 2}$ (width of the band at half maximum) of the 002-band, using equation [21,22]:

$L_{c}=\frac{0.45}{W_{1 / 2}}$

The ratio $L_{c} / d_{m}$ indicates the average number of aromatic sheets, $M_{\mathrm{e}}$. From the $W_{1 / 2}$ of the10-band the diameter of the condensed aromatic sheets, $L_{a}$, can be calculated using equation [21,22]:

$L_{a}=\frac{0.92}{W_{1 / 2}}$

The structural parameters, $d_{m}, d_{\gamma}, L_{c}, L_{a}$ and $M_{e}$ are shown in Table 2 . The structural parameters calculated show no appreciable differences in the structure of the maya and arabian asphaltenes. For all the asphaltenes studied the values of $L_{c}$, the diameter of the aromatic cluster, show values around $20 \AA$, and $M_{e}$, the average number of aromatic sheets, around 6 , in concordance with literature results $[21,22]$. The only significance difference is observed for the $L_{a}$ values, which indicates aromatic ring structures slightly more condensed for maya asphaltenes than for asphaltenes of arabian origin.

To determine the total amount of solid phase present in bitumen (asphaltenes + surfactant resins), it is necessary to know the size of the solvation layer of resins which act as surfactant. A solvation parameter $K$ has been proposed [19]. The product of the solvation parameter and the weight fraction of asphaltenes, $K w_{\text {asph }}$ is equal to the total mass fraction of solid phase in bitumen. This solvation parameter $K$ can be obtained from rheological measurements using the Roscoe law [23]:

$\eta=\eta_{m}\left(1-\frac{K w_{\text {csph }}}{\phi_{m}}\right)^{-2.5}$

where $\eta$ and $\eta_{m}$ represent the viscosity of the bitumen and the maltene matrix, respectively, and $\phi_{m}$ is the maximum packing

Table 2

Structural parameter obtained from X-ray diffraction patterns for arabian and maya asphaltenes.

\begin{tabular}{llllll}
\hline Bitumen & $\mathrm{d}_{\gamma}(\AA)$ & $\mathrm{d}_{\mathrm{m}}(\AA)$ & $\mathrm{L}_{\mathrm{c}}(\AA)$ & $\mathrm{L}_{\mathrm{a}}(\AA)$ & $\mathrm{M}_{\mathrm{e}}$ \\
\hline A17 & 4.76 & 3.57 & 19.6 & 11.5 & 5.5 \\
A570 & 4.76 & 3.57 & 22.1 & 10.6 & 6.1 \\
M18 & 4.72 & 3.57 & 21.4 & 13.7 & 6.0 \\
M172 & 4.71 & 3.57 & 20.4 & 15.3 & 5.7 \\
\hline
\end{tabular}

Table 3

$K / \phi_{m}$ values and volume fraction of solid phase, $\phi_{\text {solid }}$, for arabian and maya bitumens at $\mathrm{T}=160^{\circ} \mathrm{C}$.

\begin{tabular}{lll}
\hline Bitumen & $K / \phi_{m}$ & $\phi_{\text {solid }}(\%)$ \\
\hline M172 & 2.67 & 24 \\
M18 & 2.56 & 32 \\
A17 & 3.37 & 20 \\
A570 & 2.87 & 12 \\
A100 & 3.12 & 15 \\
A80/M20 & 2.69 & 16 \\
A60/M40 & 2.93 & 20 \\
A40/M60 & 2.83 & 22 \\
A20/M80 & 2.74 & 24 \\
M100 & 2.64 & 25 \\
\hline
\end{tabular}

fraction of asphaltene particles. Eq. (4) has been used to explain the variation of the bitumen viscosity with the temperature in the Newtonian regime [19], that is, at temperatures above $60^{\circ} \mathrm{C}$ [6]. On other hand, Eq. (4) also provides the possibility to obtain the reduced solid fraction, $K w_{a s p h} / \phi_{m}$, in the bitumen by rheological measurements. $K / \phi_{m}$ at $160^{\circ} \mathrm{C}$ have been determined for M18, M172, A17 and A570 bitumens from $\eta$ and $\eta_{m}$ measurements obtained in the temperature range $T=93-185^{\circ} \mathrm{C}$ Table 3 . The volume fraction of solid phase $\phi_{\text {solid }} \sim K w_{\text {asph }}$ for arabian and maya bitumens can be determined from $K / \phi_{m}$ values using $\phi_{m}=0.57$ corresponding to asphaltenes dispersed in toluene [19] and considering $w_{\text {asph }}$ $\sim \phi_{a s p h}$ (volume fraction of asphaltenes), given that the density of asphaltenes is very close to 1 . The values of $\phi_{\text {solid }}$ are shown in Table 3. The values of $K / \phi_{m}$ and $\phi_{\text {solid }}$ from M/A bitumen series, have been calculated from the weight percentage of maya and arabian bitumens used in their preparation (see Scheme 1). The results obtained are also shown in Table 3.

Given that maya bitumens have a higher content of asphaltenes and lower content of resins and aromatics, the values of $K / \phi$ decrease with increasing proportions of maya bitumens in M/A bitumen series. As consequence the size of the solvation shell for bitumens with high content of maya component is less than those with high content of arabian bitumens. However, since maya bitumens have higher amounts of asphaltenes, in the M/A bitumens series it is observed a gradual increase of the volume fraction of solid phase disperse in the maltene matrix. When the solvation of asphaltenes micelles is considered, all the bitumens show higher percentage of solid phase than the corresponding to the percentage of asphaltenes obtained from the SARA fractions.

SBS modified bitumens are heterogeneous systems in which the SBS is swollen in aromatic components dispersed in a maltene matrix, this maltene matrix contains less aromatics than the original bitumen and is therefore enriched in solid solvated asphaltenes. The volume occupied by swollen polymer and the volume of solid phase are important factors to take into account for understanding the stability behavior of these kinds of systems. The stability behavior of SBS modified bitumens will be analyzed below as a function of the content of solid solvated asphaltenes.

\subsection{Stability of SBS modified bitumens}

The macroscopic physical properties for SBS (3 wt\%) modified bitumens are shown in Table 4 . Fig. 4 displays the differences between top and bottom sections for SBS modified bitumens obtained from the stability tests. The data for M100 SBS (3 wt\%) was not possible to obtain due to formation of a gel upon SBS modification. An increase in the content of maya bitumen provokes a progressive increase in the difference between the softening points of the top and bottom sections of the stability tests, so that for maya bitumen contents exceeding $60 \mathrm{wt} \%$, SBS modified bitumens are clearly unstable. 
Table 4

Properties of SBS modified bitumens.

\begin{tabular}{llll}
\hline Bitumen & $\begin{array}{l}\text { Viscosity }^{\mathrm{a}} \\
\left(135^{\circ} \mathrm{C} ; \mathrm{Pa} \cdot \mathrm{s}\right)\end{array}$ & $\begin{array}{l}\text { Penetration } \\
25^{\circ} \mathrm{C} ; 0.1 \mathrm{~mm}\end{array}$ & $\begin{array}{l}\text { Softening } \\
\text { point }^{\mathrm{c}}\left({ }^{\circ} \mathrm{C}\right)\end{array}$ \\
\hline A100 & 0.986 & 75 & 62 \\
A80/M20 & 1.065 & 73 & 60 \\
A60/M40 & 1.180 & 71 & 61 \\
A40/M60 & 1.280 & 64 & 66 \\
A20/M80 & 1.637 & 60 & 76 \\
M100 & - & - & - \\
\hline
\end{tabular}

${ }^{a}$ UNE-EN 12595:2007.

b UNE-EN 1426.

C UNE-EN 1427.

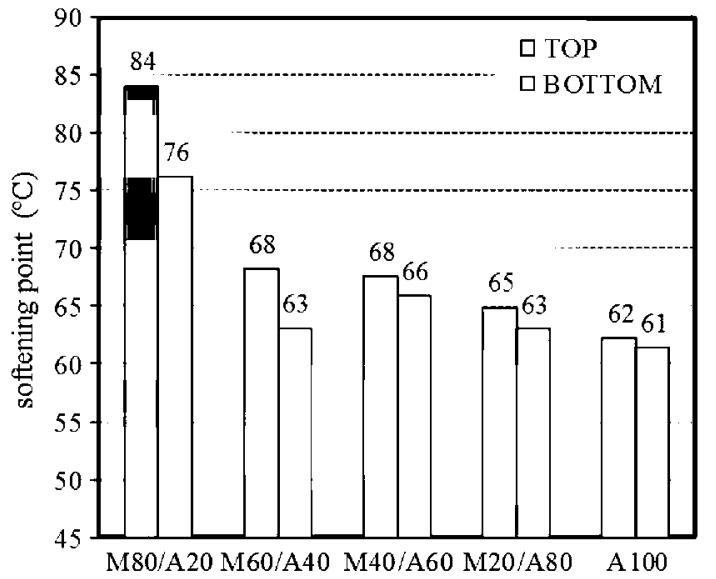

Fig. 4. Difference in softening points between top and bottom sections for SBS modified bitumens.

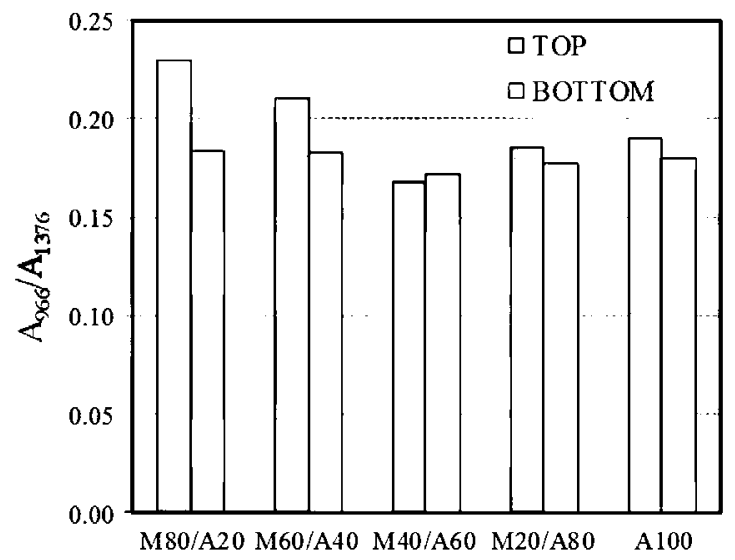

Fig. 5. FTIR area ratio, $A_{966} / A_{1376}$, for top and bottom sections for SBS modified bitumens.

FTIR spectra of PMBs have been used to explore the separation process of the SBS-bitumen samples in the stability tests. The band found at $966 \mathrm{~cm}^{-1}$ corresponding to the trans disubstituted $-\mathrm{CH}=\mathrm{CH}-$ butadiene block [24] has been used as reference. In order to make a comparison between the results for different samples, the area of the band at $966 \mathrm{~cm}^{-1}$ was normalized by the area of the band at $1376 \mathrm{~cm}^{-1}$ assigned to the bending of $\mathrm{C}-\mathrm{H}$ groups of ending $\mathrm{CH}_{3}$ present in bitumen, obtaining a butadiene index proportional to the amount of butadiene present in the samples. The results shown in Fig. 5 indicate that an enrichment of bitumen with maya component above $40 \mathrm{wt} \%$ provokes the migration of the SBS polymer towards top section, which is reflected by an increase of the difference between the value of $A_{966} / A_{1376}$ for the top and bottom sections. These results agree with those obtained from the softening points and imply that the FTIR technique is suitable for determining the stability of bitumen-SBS systems.

Although the macroscopic properties of the bitumens belonging to M/A series are similar (see Table 1), the physical macroscopic properties of SBS modified bitumens (see Table 4) and their stability behavior are significantly different. This differentiating behavior can be explained by the differences in the composition and structure of the bitumens. The amount of the aromatic fractions increases around $25 \%$ going from M100 bitumen to A100 bitumen (see Fig. 2) making the interaction with SBS blocks more favorable.

On the other hand the fraction of solid volume dispersed in the maltene matrix increases $67 \%$ going from A100 bitumen to M100 bitumen (see Table 3). It is also important to consider that this increase will be even greater if the decrease of the aromatic fraction provoked by the swelling of the polymer is taken into account. These two factors (composition of maltene matrix and increase in solid volume fraction) have certainly influence when it comes to analyze the changes observed on the stability SBS-bitumen as seen for M80/A20 and M100 bitumens.
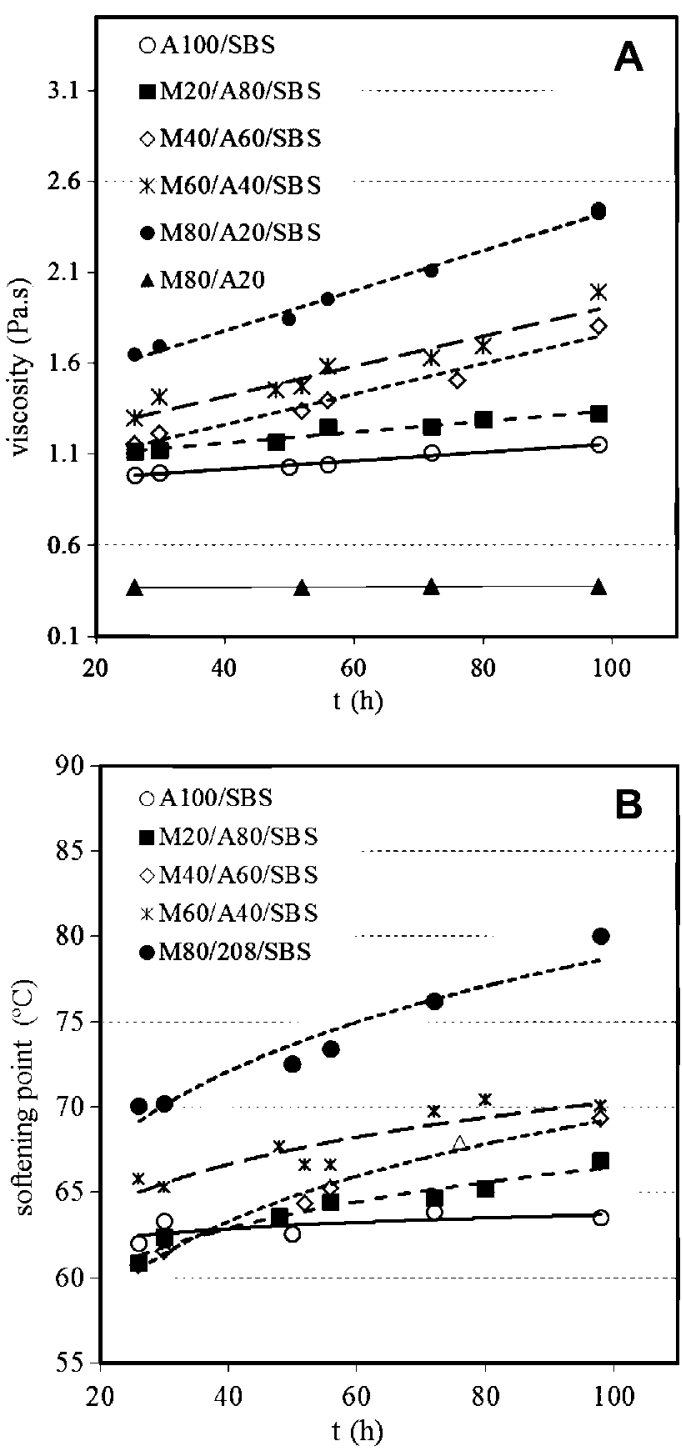

Fig. 6. Variation of macroscopic physical properties of SBS modified bitumens stored at $T=160^{\circ} \mathrm{C}$ as a function of storage time. (A) viscosity; (B) softening points. 

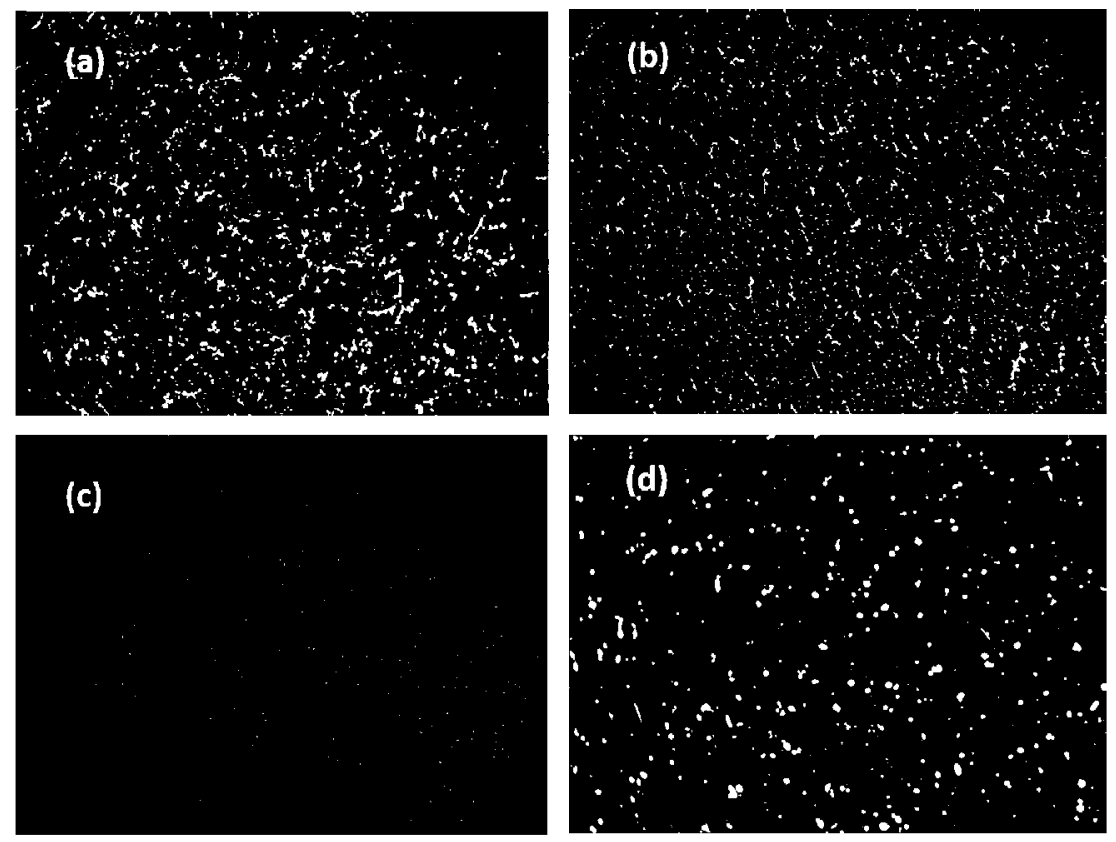

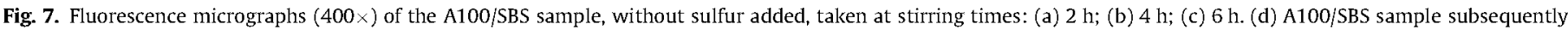
stored $20 \mathrm{~h}$ at $T=160^{\circ} \mathrm{C}$.

\subsection{Storage stability of SBS modified bitumens}

From a practical point of view one of the major limitations of the PMBs is the lack of stability when they are stored for long periods of time at high temperatures. This situation facilitates the diffusion and may even provoke polymer phase separation due to the difference in density between SBS and bitumen. The tendency to phase separation causes changes in the physical properties of these systems that they can become critical for practical applications.

In order to evaluate changes in the behavior of SBS-bitumen systems, viscosity and softening points have been determined as a function of storage time at $160^{\circ} \mathrm{C}$. The results are shown in Fig. 6 .
It can be seen that the bitumen-SBS systems stored at $160^{\circ} \mathrm{C}$ evolve over time provoking a continuous rise of the viscosity and softening point. It is also observed that the evolution of the systems is more noticeable in those with higher content of maya bitumen.

To attempt to explain this behavior the changes in the structure of neat bitumen were considered. At high temperature oxidation could provoke an increase in viscosity and softening point when neat bitumen undergoes the same treatment as PMB samples. Fig. 6 shows the behavior of M80/A20 bitumen when it is subjected to the same thermal treatment, showing that the changes observed in the PMBs systems cannot be attributed to changes in the properties of neat bitumen.
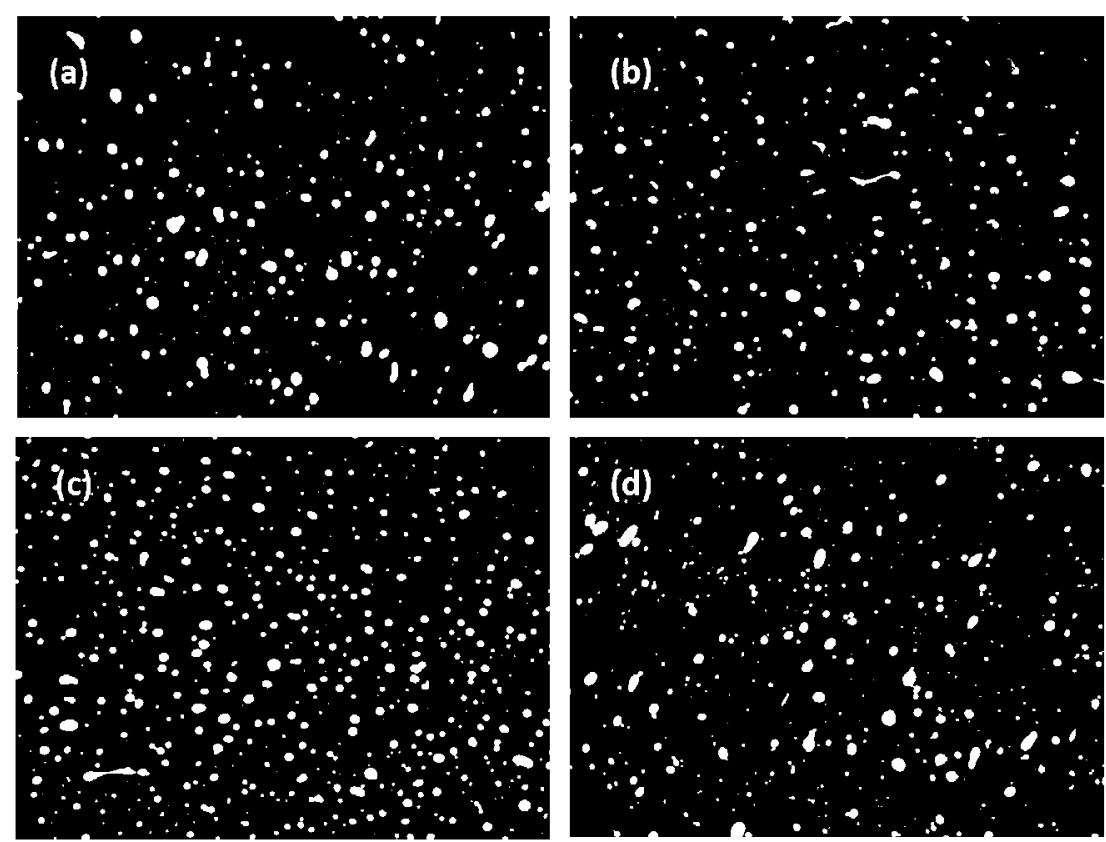

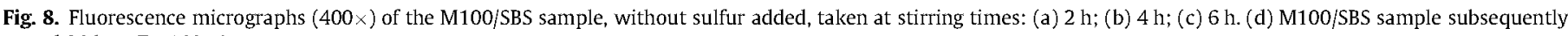
stored $20 \mathrm{~h}$ at $T=160^{\circ} \mathrm{C}$. 

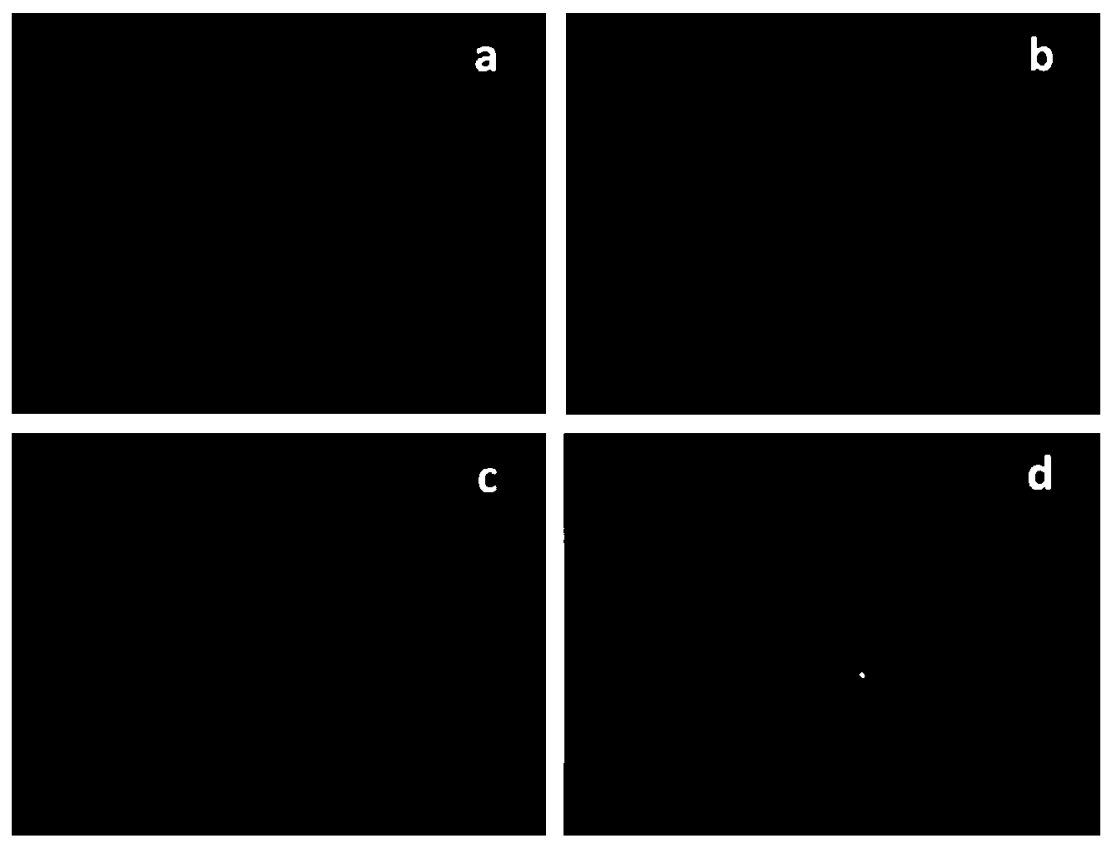

Fig. 9. Fluorescence micrographs ( $400 \times$ ) of the A100/SBS sample estabilized by sulfur and stored at $T=160^{\circ} \mathrm{C}$, taken at storage times: (a) $26 \mathrm{~h}$; (b) $30 \mathrm{~h}$; (c) $50 \mathrm{~h}$; (d) $72 \mathrm{~h}$.
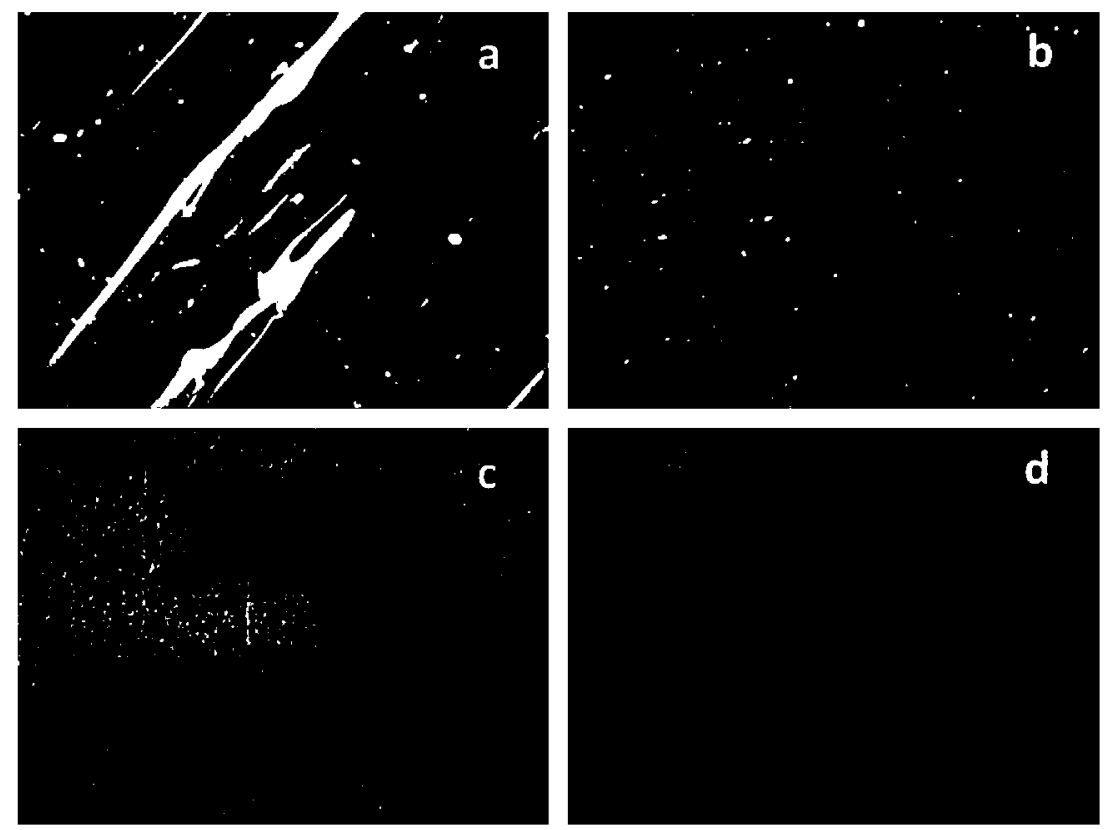

Fig. 10. Fluorescence micrographs $(400 \times)$ of the M80/A20/SBS sample estabilized by sulfur and stored at $T=160^{\circ} \mathrm{C}$, taken at storage times: (a) $26 \mathrm{~h}$; (b) $30 \mathrm{~h}$; (c) $50 \mathrm{~h}$; (d) $72 \mathrm{~h}$.

Fluorescence microscopy allows observation of the dispersed polymer phase in the bitumen, showing the areas containing polymer in white color, while black color corresponds to bitumen areas. In order to analyze the morphological changes of bitumen/SBS systems, Figs. 7 and 8 show micrographs of the A100/SBS and M100/ SBS systems. These micrographs were taken during the mixing process and upon subsequent storage at $160^{\circ} \mathrm{C}$ for $20 \mathrm{~h}$, without the addition of sulfur. In order to reflect, as accurately as possible the morphology of bitumen/SBS system, the micrographs were taken of fresh samples immediately after being cooled quenched. Similarly, micrographs of the A100/SBS and M80/A20/SBS, show in
Figs. 9 and 10 , were taken after the addition of sulfur during storage at $T=160^{\circ} \mathrm{C}$.

Fig. 7 shows the dispersion of SBS in A100 bitumen over the mixing time, the micrographs show that the system forms a uniform dispersion of very small particles within the bitumen. On the contrary M100/SBS samples (Fig. 8), subjected to the same mixing process, show a dispersion of particles with size significantly higher than those corresponding to the system A100/SBS. The micrographs of these samples subsequently stored at $T=160^{\circ} \mathrm{C}$ for $20 \mathrm{~h}$ (Figs. $7 \mathrm{~d}$ and $8 \mathrm{~d}$ ) show that in the absence of sulfur both systems evolve towards similar morphologies. However it is 
possible to observe that, the average particle size of SBS polymer phase in the A100/SBS sample is slightly lower than in the M100/ SBS sample, which could be indicative that SBS reaches a lower swelling degree in the maltene matrix of A100 bitumen.

The observation of the bitumen/SBS samples without sulfur may be helpful to explain the stability and storage behavior of the samples stabilized with sulfur. When sulfur is added to SBS/ bitumen samples reacts with the alkene moieties of SBS, creating chemical crosslinks that stabilize the system. Due to the higher level of dispersion of the polymeric phase and the lower degree of swelling of SBS in A100 bitumen the accessibility of the SBS alkene groups to react with the sulfur will be greater, and consequently the efficiency of the reaction with sulfur will increase. This can be observed in Fig. 9 corresponding to the A100/SBS sample stored at $T=160^{\circ} \mathrm{C}$ after being stabilized by vulcanizing sulfur. However, poorer dispersion of SBS in M80/A20 bitumen provokes that the vulcanizing sulfur reaction is not so effective. Fig. 10 shows the evolution of the M80/A20/SBS sample as a function of storage time at $T=160^{\circ} \mathrm{C}$, where it is possible to distinguish, at long storage times $(72 \mathrm{~h}$ ), discrete polymer domains in agreement with a more heterogeneous system. These results agree with stability test discussed above.

These microscopy observations also agree with viscosity and softening points results (Fig. 6). Due to the low percentage of solid phase (asphaltene solvated by solid resins) and high amount of aromatics (see Table 3 and Fig. 2), bitumen with high content of arabian component, such as A100 bitumen and M20/A80 bitumen, show a good interaction with SBS which facilitates its stabilization by sulfur vulcanization. In this situation the macroscopic properties of such SBS modified bitumen remain practically stable during storage at high temperatures, and therefore are suitable for practical applications. On the other hand, the higher the content of maya bitumen in the mixture, the poorer is the interaction with SBS. Higher content of solid phase (asphaltene solvated by solid resins) and lower aromatic proportion leads to lower polymer dispersion making sulfur stabilization less efficient in systems with higher maya content. These systems show significant changes in their macroscopic properties during storage at high temperature, becoming unstable when the amount of maya bitumen is higher than $60 \mathrm{wt} \%$

\section{Conclusions}

Good storage stability at high temperature for SBS modified bitumen, depends on the structural parameters of bitumen used in their preparation. The bitumens used in this work display similar values in their physical macroscopic properties, suitable for polymer modification, and similar asphaltene structures, but show evident differences in stability behavior in the presence of a radial SBS modifier. Significant changes in aromatic content and in the percentage of solid phase (asphaltene solvated by solid resins) dispersed in maltene matrix are responsible of this behavior. The results show that a good interaction of SBS modified-bitumen needs, in these preparatory conditions, the presence of aromatic contents around $40 \mathrm{wt} \%$, and solid phase volume, $\phi_{\text {solid, }}$ lower than $22 \%$.

\section{References}

[1] Nellensteyn FJ. The constitution of asphalt. J lnst Pet Technol 1924;10:311-25

[2] Pfeiffer JP, Saal RNJ. Asphaltic bitumen as colloid systems. J Phys Chem 1940;44:139-49.

[3] Petersen JC, Robertson RE, Branthaver JF, Harnsberger PM, Duvall JJ, Kim SS, et al. Binder characterization and evaluation, vol. 1. SHRP report A-367. Washington, DC: National Research Council; 1994.

[4] Christensen DW, Anderson DA. Rheological evidence concerning the molecular architecture of asphalt cements. In: Proceedings chemistry of bitumen, vol. 2. Rome; 1991. p. 568-95.

[5] Redelius P. The structure of asphaltenes in bitumen. Road Mater Pave Des 2006:143-62 [special issue EATA 2006].

[6] Lesueur D. The colloidal structure of bitumen: consequences on the rheology and on the mechanisms of bitumen modification. Adv Colloid Interface Sc $2009 ; 145: 42-82$.

[7] Fu H, Xie L, Dou D, Li L, Yu M, Yao S. Storage stability and compatibility of asphalt binder modified by SBS graft copolymer. Constr Build Mater $2007 ; 21: 1528-33$

[8] Chen JS, Huang CC. Fundamental characterization of SBS-modified asphalt mixed with sulphur. J Appl Polym Sci 2007;103:2817-25.

[9] Larsen DO, Alessandrini JL, Bosch A, Cortizo MS. Micro-structural and rheological characteristics of SBS-asphalt blends during their manufacturing. Constr Build Mater 2009;23:2769-74.

[10] Yildirim Y. Polymer modified asphalt binders. Constr Build Mater 2007;21:66-72

[11] Sengoz B, Isikyakar G. Analysis of styrene-butadiene-styrene polymer modified bitumen using fluorescent microscopy and conventional test methods. J Hazard Mater 2008;150:424-32.

[12] Wen G, Zhang Y, Zhang Y, Sun K, Chen Z. Vulcanization characteristics of asphalt/SBS blends in the presence of sulphur. J Appl Polym Sci 2001;82:989-96.

[13] Wua S, Pang L, Moa L, Chen Y, Zhu G. Influence of aging on the evolution of structure, morphology and rheology of base and SBS modified bitumen. Constr Build Mater 2009;23:1005-10.

[14] Zhang F, Yu J, Wu S. Effect of ageing on rheological properties of storage-stable SBS/sulfur-modified asphalts. J Hazard Mater 2010;182:507-17.

[15] Zhang F, Yu J, Han J. Effects of thermal oxidative ageing on dynamic viscosity TG/DTG, DTA and FTIR of SBS- and SBS/sulfur-modified asphalts. Constr Build Mater 2011;25:129-37.

[16] Luo W, Chen J. Preparation and properties of bitumen modified by EVA graft copolymer. Constr Build Mater 2011;25:1830-5.

[17] Lu X, Isacsson U. Modification of road bitumens with thermoplastic polymers. Polym Testing 2001;20:77-86.

[18] Sengoz B, Topal A, Isikyakar G. Morphology and image analysis of polymer modified bitumens. Constr Build Mater 2009;23:1986-92.

[19] Storm AS, Ronald J, Barresi, Sheu EY. Rheological study of Ratawi vacuum residue in the 298-673 K temperature range. Energy Fuels 1995;9:168-76.

[20] Lesseur D, Gérard JF, Claudy P, Létoffé JM, Plance JP, Martin D. Relationship between structure and the mechanical behaviour of paving grade asphalt cements. J Assoc Asphalt Paving 1997;66:486-507.

[21] Yen TF, Erdman JG, Pollack SS. Investigation of structure of petroleum asphaltenes by X-ray diffraction. Anal. Chem. 1961;33:1587-93.

[22] Christopher ], Sarpal AS, Kapur GS, Krishna A Tyagi BR, Jain MC et al. Chemica structure of bitumen-derived asphaltenes by nuclear magnetic resonance spectroscopy and X-ray diffractometry. Fuel 1996;75:999-1008.

[23] Roscoe R. The viscosity of suspensions of rigid spheres. $\mathrm{Br} J$ Appl Phys $1952 ; 3: 267-9$.

[24] Masson JF, Pelletier L, Collins P. Rapid FTIR method for quantification of styrene-butadiene type copolymers in bitumen. J Appl Polym Sci 2001;5:1034-41. 